\title{
DETEÇÃO DE INCÊNDIOS
}

\section{EM TÚNEIS RODOVIÁRIOS.}

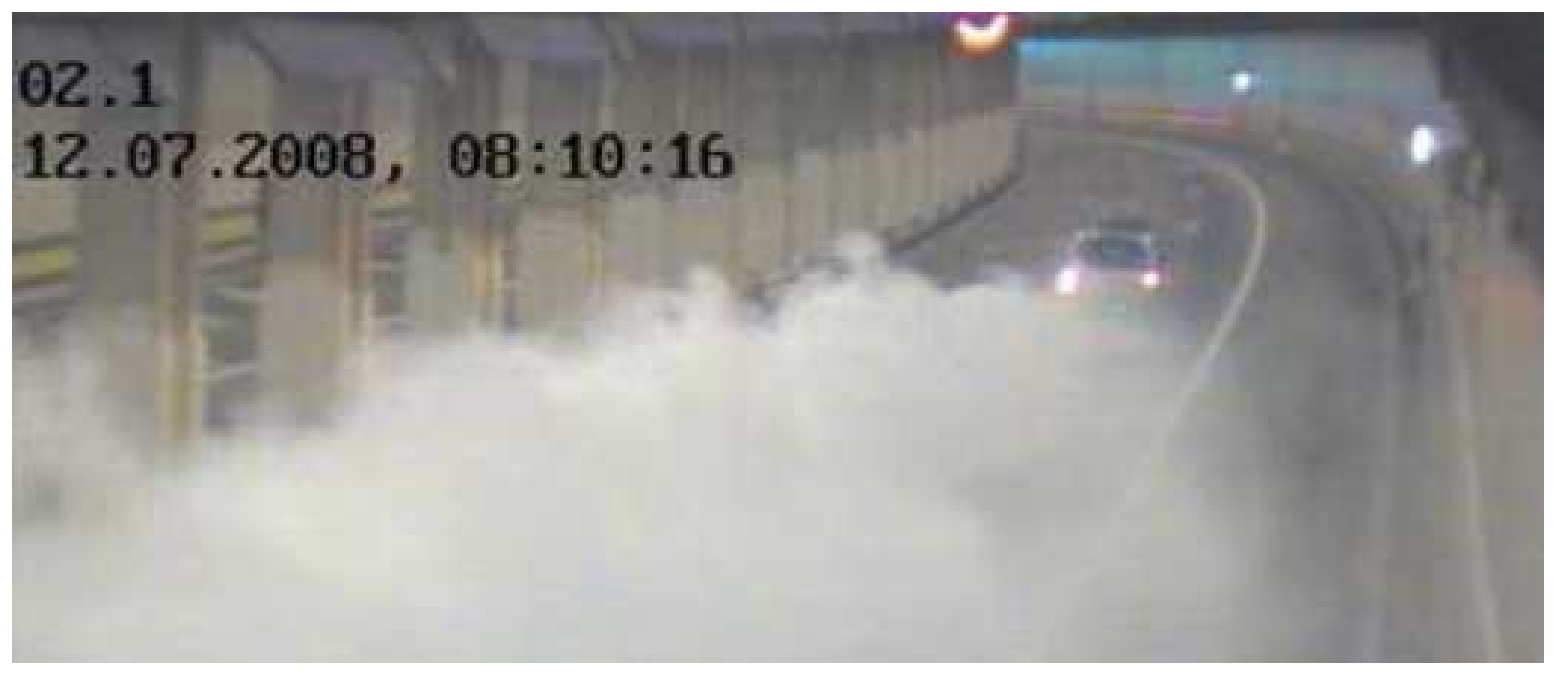

\section{Resumo}

Incêndios em Túneis rodoviários podem ter custos brutais não só em perdas de vidas humanas como também nos custos de operação e de reparação do túnel!

$\mathrm{Na}$ maioria dos casos a libertação de fumos é a principal causa de morte pela inalação de gases tóxicos, muito à frente dos problemas causados por queimaduras devido ao incêndio.

Os convencionais cabos térmicos detectam o incêndio por variação de temperatura mas com grande atraso quando comparados com detectores de fumo Fireguard.

\section{Generalidades}

Em 1999, a ocorrência de um fogo num camião no túnel de Montblank (Itália- França), provocou a morte de 41 pessoas e teve prejuízos de cerca de 900 milhões devido a interrupção do túnel e aos trabalhos de manutenção.

Em 2001, devido a uma colisão de camiões no túnel de Gothard na Suíça , 11 pessoas morreram e os custos foram de 11 milhões de euros.
Em 2008, um fogo num camião de químicos no Eurotúnel (Inglaterra - França) teve um prejuízo de 260 milhões.

Na maioria dos incidentes em túneis rodoviários, a principal causa de morte é por inalação de gases tóxicos e não por temperatura.

As principais causas destes incidentes são devidos a sobreaquecimento dos motores, a falhas no sistema de travagem, falhas nos turbocompressores, pneus defeituosos, que originam grande libertação de fumo, tornando a visibilidade drasticamente reduzida. Nestas condições, os detetores lineares de temperatura não respondem porque só funcionam com fogo aberto e por variação de temperatura, e os sistemas de vídeo são pouco eficazes porque emitem falsos alarmes devido à falta de contraste e à reflexão de luz devido à imensa nuvem de fumo.

A necessidade de instalar detetores de fumo está bem enfatizada na legislação de vários países, em especial documentada pela FEDRO - entidade rodoviária Suíça.

Os detetores de fumo devem ser distanciados de cerca de $100 \mathrm{~m}$, não devem emitir mais do que um falso alarme por ano, e não devem ter interferências devido a nevoeiro. 


\section{Sistema Fireguard}

O Fireguard está instalado, com sucesso, desde 2007 em milhares de pontos em vários túneis, nomeadamente o de Gothard e Montblank, deteta fumos pelo principio de "back scater ligth", tem extrema fiabilidade e requer mínimo de manutenção.

A figura 1 mostra um sistema de deteção de fumo Fireguard.

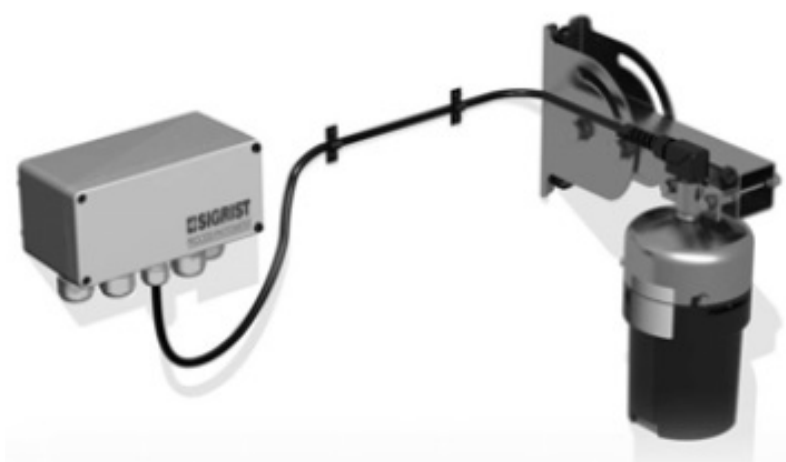

Figura 1. Sistema de deteção de fumo Fireguard
Para além da deteção de fumo, o Fireguard pode incorporar detetor de temperatura e assim verificar se existe só libertação de fumos ou se também incêndio.

Testes feitos com fogo real numa viatura e com o Fireguard a $62,5 \mathrm{~m}$ e outro a $125 \mathrm{~m}$ de distância mostram a grande diferença no tempo de deteção de incêndio em comparação com o cabo térmico.

A figura 2 mostra os resultados de um ensaio de fogo real realizado numa viatura, com detetores Fireguard e cabo térmico linear.

A linhas verticais 1 e 2 marcam o mínimo tempo possível de alarme baseado na velocidade do vento e na distância dos detetores Fireguard a $62,5 \mathrm{~m}$ e a $125 \mathrm{~m}$ da viatura.

A linha horizontal ponteada marca o nível estabelecido para o alarme.

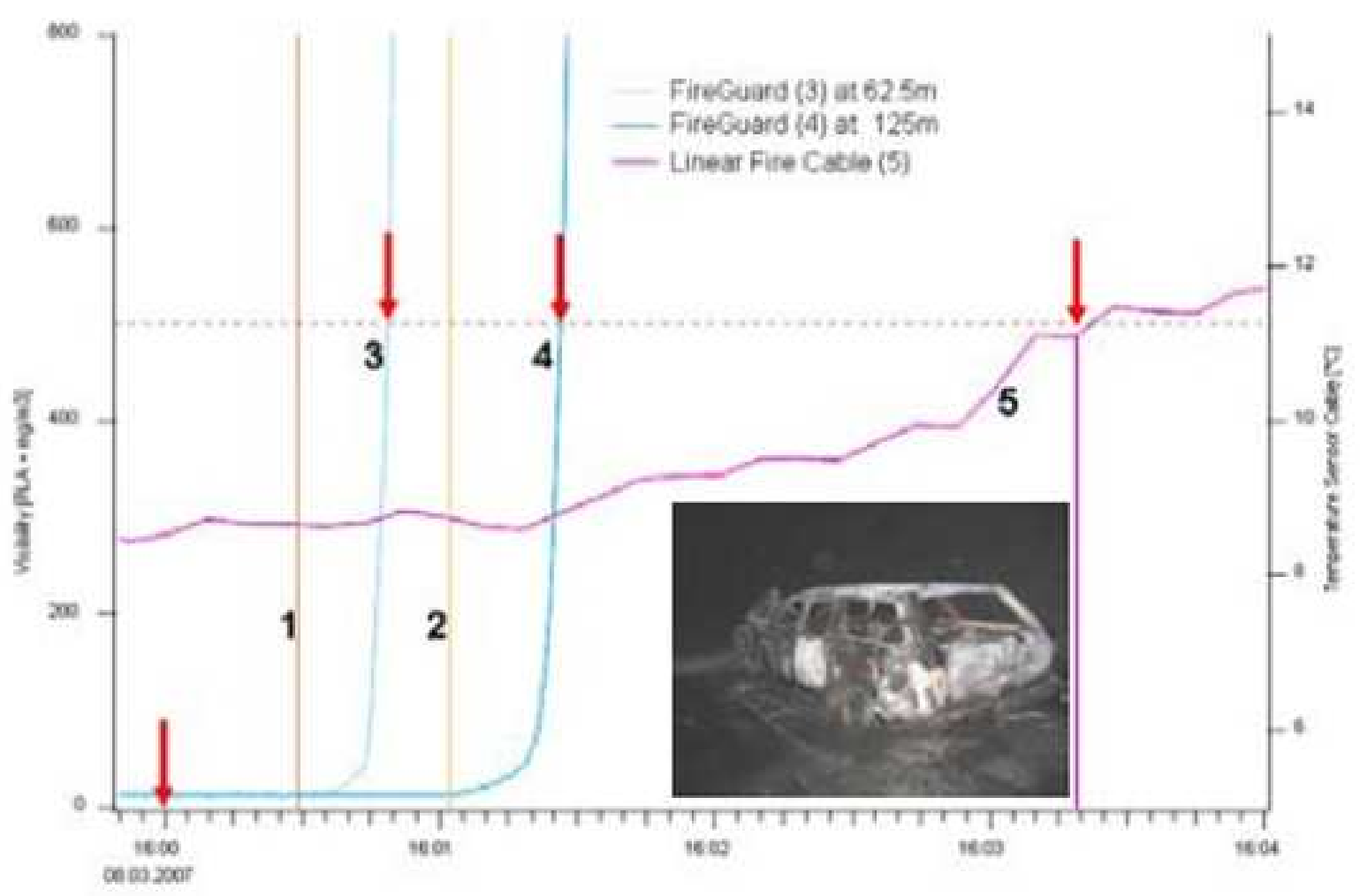

Figura 2. Ensaio de fogo real realizado numa viatura com detetores Fireguard e cabo térmico linear 


\section{ARTIGO TÉCNICO}

As linhas 3 e 4 mostram o aumento de intensidade do sinal do Fireguard para ambos os detetores.

O alarme foi atuado nos 2 Fireguard após 20 segundos.

No cabo térmico o alarme só é dado após 3 minutos - só depois de haver já fogo aberto.

\section{Observações finais}

O Fireguard está instalado com sucessores em milhares de pontos em túneis na Europa e representa a solução atual mais segura para a deteção precoce de incêndios.

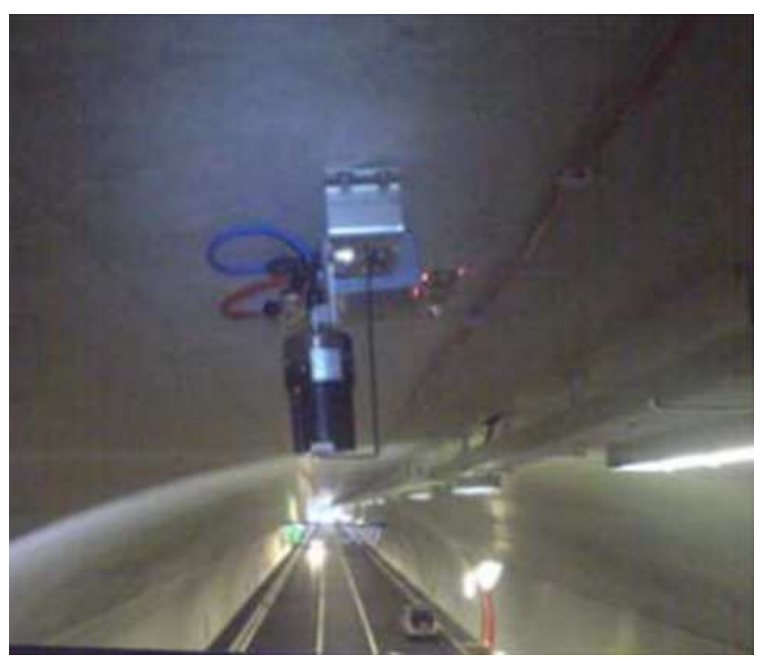

Curiosidade:

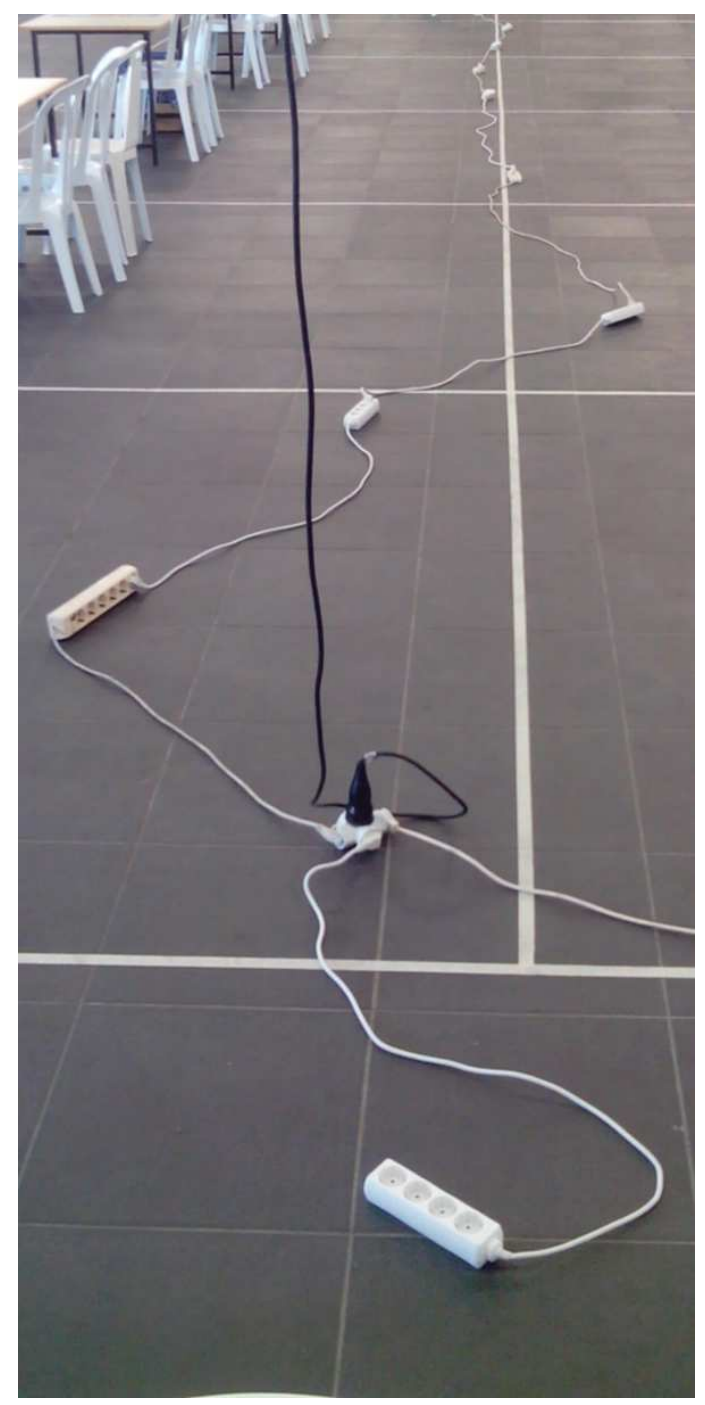

